\title{
Application of Wavelet Threshold Denoising in High-speed Rail Data Processing in Alpine Region
}

\author{
Zhou Peng, Wang Jianmin, Yang Jianchao, Wang Gang, Tang Zhenbin \\ Liaoning Technical University, School of Geomatics \\ Fuxin, Liaoning, 12300
}

\begin{abstract}
In alpine regions, a series of external factors may result in error in observing data of the high-speed rail. Based on traditional high-speed rail subsidence and deformation monitoring methods, this article aims at denoising processing of observing data of Harbin-to-Dalian high-speed rail(Siping section), in which the wavelet threshold denoising method was adopted. Comparing the denoising results of the hard and the soft threshold function, we put up a new method, which preprocessed the raw data with fuzzy control filter. As the results showed, the method could sensitively recognize the noise without prior knowledge, therefore, it is suitable for high-speed rail subsidence and deformation data processing in alpine regions.
\end{abstract}

Keywords-subsidence and deformation monitoring, denoising, wavelet analysis, threshold function

\section{INTRODUCTION}

As the speed is above 200 kilometers, high-speed rail has strict design parameters and accuracy indicators[1], which require high quality of subsidence and deformation monitoring. While the severe climate in alpine regions including low temperature, unstable atmosphere, thawing of the permafrost, strong wind, etc, may result in error in observing data. Undoubtedly, errors would affect the following processing procedures. As it's necessary to recognize the error and then remove it, we attempt to apply the wavelet threshold denoising method which aims at removing the noise caused by external factors in signal processing to subsidence and deformation data processing in alpine regions.

\section{SUBSIDENCE AND DEFORMATION MONITORING OF}

\section{HIGH-SPEED RAILWAY}

\section{A. Contents of subsidence and deformation monitoring}

According to specifications[TB10017-99], main contents of subsidence and deformation monitoring are roadbeds, bridges, culverts and the transition sections. More specifically, the roadbeds contain subgrades, subgrade bases, hard shoulders, embankments and cuttings; the bridges contain cushion caps and pier bodies; transition sections contain the transition sections between roads and bridges, roads and culvets, bridges and culvet, etc[1].

\section{B. Establishment of monitoring network}

The monitoring network of high-speed rail contains the horizontal and vertical displacement monitoring network.

The former is established in an independent coordinate system with GPS receivers and acquired accuracy(the national third-class horizontal displacement monitoring network). Based on the bedrock points, deeply buried benchmarks and ordinary benchmarks(provided by the Railway Institute), the vertical displacement monitoring network should be extended to a certain density for further benchmarks encryption and setting of working base points. And it should be in accordance with the specifications for the first and second order leveling[2].

According to the Railway roadbed construction acceptance level [3], relevant departments made a strict regulations on general allowable deformation(postconstruction), including allowable deformation of even or uneven foundation structure (every $20 \mathrm{~m}$ ), the faulting slab resulting from the settlement differences between roadbeds and bridges, and folding angles between rail structure units, etc.

\section{Settlement of monitoring points}

Monitoing points contains three types, reference points, working points and settlement distortion points.

Reference points are required to be settled in stable area, having good stability, and are bedrock points or deeply buried benchmarks with second-class leveling control precision.

Working points are transferring points of coordinates and elevations when determining the settlement distortion points, so they are required to stand stable during the monitoring period. Spacing between reference points(including working points)is about 200 meters in order to meet the requirements of vertical displacement monitoring.

Settlement distortion points are buried directly into the settlement-deformation entities. They should be setted in specific parts of the entities thus can reflect their settlement, firmly settled, convenient for observation, structure reasonable, and do not affect the appearance and usage of the entities[4][5].

\section{Measurement and data processing}

Measuring with qualified instruments by forming roundtrip line or closed loop with required accuracy[2] with closing check conditions for each measurement. Processing the data with qualified software and re-measurement is 
required if the closing error or mean error is beyond the requirement.

\section{3 REASEARCH ON SUBSIDENCE AND DEFORMATION}

\section{DATA PROCESSING}

\section{A. Noise(error) resources of raw data}

Severe climate in alpine region: low temperature, thawing of ice or snow, unstable atmosphere, etc, all are noise resources of monitoring data. Here the formula show constitution of the true deformation.

true deformation $=$ measurement error + noise

Practical analysis shows that noise in high-speed rail subsidence and deformation monitoring are very similar to that in electronic signal processing, so we attempt to apply the wavelet threshold denoising method in it to noise processing of subsidence and deformation data.

\section{B. Wavelet threshold denoising method}

\section{1) Introduction of wavelet threshold denoising}

In wavelet threshold denoising, if the original signal is $\mathrm{f}(\mathrm{t})$ and the polluted signal is $\mathrm{w}(\mathrm{t})$, then the observing signal can be expressed as following:

$$
\mathrm{w}(\mathrm{t})=\mathrm{f}(\mathrm{t})+o{ }^{\circ} \mathrm{e}(\mathrm{t})[6]
$$

Where e(t) for the noise, and ó for the noise intensity.

Sample the original signal $f(t)$ and get discrete $f(n), n=0$, $1,2, \ldots, \mathrm{N}-1$. Perform wavelet transformation with lowpass filter and high-pass filter respectively, then the noise would show strong randomness and it can be considered to be in accordance with Gaussian distribution. In Gaussian distribution, coefficients of majority noise(99. 99\%) are located in the interval[-3*T, $3 * \mathrm{~T}](\mathrm{T}$ is the assumed threshold). Therefore, denoised signal can be obtained if the error is processed ${ }^{[6]}$.

For different handling ways of the error in[-3*T, $3 * \mathrm{~T}]$, wavelet thresholding method is classified to hard thresholding and soft thresholding method.

\section{2) Hard thresholding and soft thresholding method}

Dohono D. L and Professor Johnstone raised threshold denoising method (wavelet shrinkage) in 1995, followed by the proposal of hard and soft threshold functions.

Hard-threshold function[7]:

$$
\mathrm{w}^{\prime}{ }_{\mathrm{m}}=\left\{\begin{array}{l}
\mathrm{w}_{\mathrm{m}},\left(\mathrm{w}_{\mathrm{m}} \geq \mathrm{T}\right) \\
0,\left(\mathrm{w}_{\mathrm{m}}<\mathrm{T}\right)
\end{array}\right.
$$

Where $\mathrm{w}_{\mathrm{m}}$ is coefficients of wavelet, $\mathrm{W}^{\prime} \mathrm{m}$ is coefficients of the estimated wavelet. It shows that it compares coefficients of decomposited wavelet and the given $\mathrm{T}$ in hard-threshold method. Coefficient of wavelet remains unchanged if it's greater than or equal to the $T$, while it is resetted to 0 if it's less than the $T$.

Soft-threshold function[7]:

$\mathrm{w}_{\mathrm{m}}^{\prime}=\left\{\begin{array}{l}\operatorname{sgn}\left(\mathrm{w}_{\mathrm{m}}\right)\left(\mathrm{w}_{\mathrm{m}}-\mathrm{T}\right),\left(\left|\mathrm{w}_{\mathrm{m}}\right| \geq \mathrm{T}\right) \\ 0,\left(\left|\mathrm{w}_{\mathrm{m}}\right|<\mathrm{T}\right)\end{array}\right.$
Unlike hard-threshold function, the value that compared with $\mathrm{T}$ is not coefficient of wavelet, but its absolute value in soft-threshold function. Coefficient of wavelet is resetted to 0 if it's less than $T$, and it is setted to the difference between itselt and $T$ (no change of sign) if it's not less than $T$.

\section{Application of the wavelet threshold denoising method in high-speed rail subsidence and deformation data processing}

Here is processing result of some subsidence and deformation data of Harbin-to-Dalian high-speed rail(Siping section)with hard and soft threshold function respectively. Wavelet function is sym4 and set the threshold $\mathrm{T}$ by hierarchical threshold selection[8] and the decomposition layers is 2 . Here the table below is denoising performance comparison.

TABLE II. NOISE REDUCTION PERFORMANCE COMPARISON OF THE TWO THRESHOLD FUNCTIONS

\begin{tabular}{ccc}
\hline & $\begin{array}{c}\text { Signal to noise } \\
\text { ratio (SNR) }\end{array}$ & $\begin{array}{c}\text { mean square } \\
\text { error (MSE) }\end{array}$ \\
\hline $\begin{array}{c}\text { soft threshold } \\
\text { function }\end{array}$ & 22.7679 & 0.0433 \\
\hline $\begin{array}{c}\text { Hard threshold } \\
\text { function }\end{array}$ & 23.9637 & 0.0356 \\
\hline
\end{tabular}

Denoising effect is shown in the figure below.
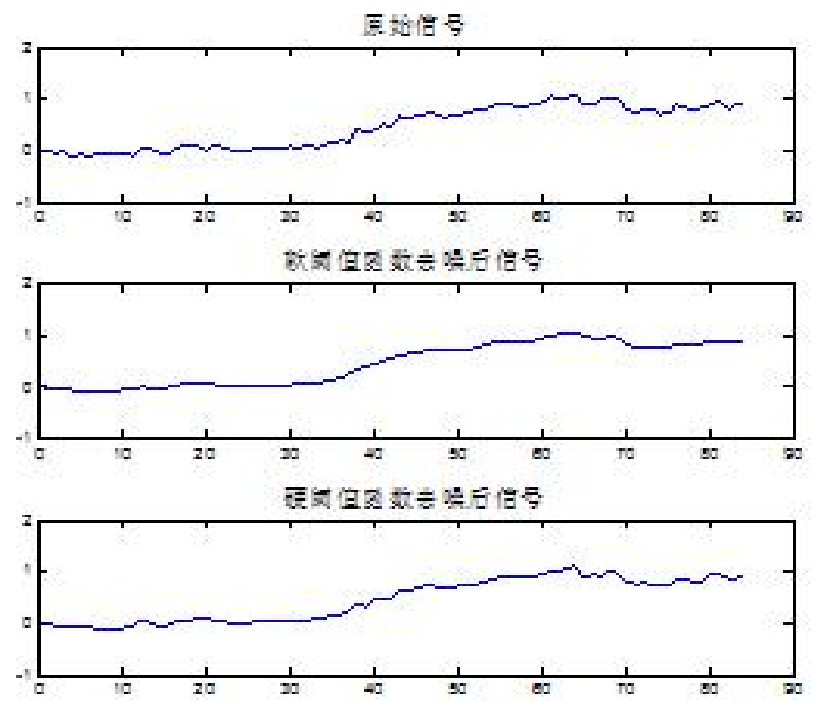

Figure 1. denoising effect charts of the two threshold functions

Conlcluded from the table and charts above, the soft threshold function has better continuity in the denoised data, while compressing the coefficients which are greater than $\mathrm{T}$, it has notable error between processed data and the original data. On the other hand, the hard threshold function weakens the continuity, resulting in mutations of the reconstruction signal. Therefore, this paper presents a new 
method, with combination of fuzzy control filter and threshold function.

\section{Combination of fuzzy control filter and threshold function}

Wavelet threshold denoising method converts the signal with wavelet transformation, and then separate the noise from signal according to characteristics of converted signal and coefficients of the wavelet[8]. Separation will be difficult when variance of the noise is great, and this would reduce the performance of wavelet denoising and it can't be brought into full play. As the fuzzy theory[9] not only reduces variance of the noise, but also can well remain details of signal, it may have unique advantage when dealing with such issues. As a result, the denoised signal is closer to the real value and has a higher accuracy of correlation coefficient. Its basic idea is to perform preprocessing of the signal with fuzzy control filter to guarantee small difference between the original signal and decrease variance of the white noise meanwhile.

Supposing $W_{i}$ is a sample signal, in the formula $W_{i}=s_{i}+e_{i}, s_{i}$ for useful signal, ${ }^{e}{ }_{i}$ for noise and $i$ for discrete sampling points[10]. Eliminating the noise and thus we obtain the useful signal[10]. Smoothing method based on fuzzy control parameters is:

$$
s_{i}=\alpha W_{i}+(1-\alpha) s_{i-1}, \quad s_{1}=W_{2} \quad \alpha \in(0,1)
$$

In the formula, if the signal doesn't have noise, then the parameter $\alpha$ equals to 1 , but if the noise exists, then $\alpha$ ranges from 0 to 1 . The larger the noise is, the smaller $\alpha$ is, thus whether the denoising result is good or bad all depends on $\alpha$. When $\alpha$ is too large, attenuation of $^{e_{i}}$ is not great and the signal-to-noise ratio(SNR) is poor. When $\alpha$ is too small, the noise will be well controlled but the deformation of the useful signal ${ }^{s_{i}}$ will be notable.

An important indicator of weighing stability of the high railway roadbeds and bridges as well as ascertaining the right time to lay rail is that the correlation coefficient of time and the settlement must be bigger than 0. 92. We obtained good correlation coefficient using this method when processing some data of the project(Harbin-to-Dalian high-speed rail(Siping section)). Here is the results.

\section{IV. . SUMMARIES}

When denosing raw data in high-speed-rail, both soft and hard threshold functions have some shortcomings. The new threshold denoising method, which combining the fuzzy control filter with threshold function, could reduces the variance of noise and make full use of the two threshold functions. Results showed that the correlation coefficient and effect were better than that of purely using soft or hard threshold function. It may be applied to high-speed-rail subsidence and deformation data processing.

\section{REFERENCES}

[1] Passenger Special Line Ballastless Track Engineering Survey Provisions[S]. Railway Construction[2006] 189

[2] Specifications for the first and second order leveling[S]. (GB1289791)

[3] Railway roadbed construction acceptance level[S]. Railway Construction[2007] 159

[4] New Harbin-Dalian Railway Passenger Special Line Deformation Monitoring System Regulations[R]. 2007

[5] Technical guidelines for track laying conditions of ballastless special line[R]. Railway Construction[2006] 158

[6] Xu Chen, Zhao Ruizhen, Gan Xiaobing. Wavelet analysis and its algorithm[M]. Beijing: Science Press , 2004:64-108

[7] Wu Junming. Discussion on application and prospects of wavelet analysis theory[J]. Journal of Changchun University of Science and Technology, 2005, 1(2):146-158

[8] He Xiufeng. New methods and application of deformation monitoring[M]. Beijing:Science Press, 2007

[9] Wang Hongyan, Shao Yukui, Zhang Hai, Qi Fengguang. Denoising analysis of power quality disturbances based on wavelet threshold method[J]. Journal of Taiyuan University of Technology, 2006.

[10] Wang Xin, Zhu Gaozhong. Study of a new wavelet threshold method in signal denoising[J]. High Voltage Engineering, 2008, 34(2):342345

TABLE I. HIGH-SPEED RAIL TRACK POST-CONSTRUCTION SETTLEMENT CONTROL STANDARDS[3]

\begin{tabular}{ccccc}
$\begin{array}{c}\text { general allowable } \\
\text { deformation }\end{array}$ & $\begin{array}{c}\text { Allowable deformation } \\
\text { (even foundation) }\end{array}$ & $\begin{array}{c}\text { Uneven } \\
\text { deformation }\end{array}$ & Faulting & Folding \\
\hline$\leq 15 \mathrm{~mm}$ & $\leq 30 \mathrm{~mm}$ & $20 \mathrm{~mm} / 20 \mathrm{~m}$ & $\leq 5 \mathrm{~mm}$ & $<1 / 1000$ \\
\hline
\end{tabular}


TABLE III. COMPARISON OF THE CORRELATION COEFFICIENT OBTAINED WITH VARIOUS DENOISING METHODS

\begin{tabular}{ccc}
\hline & Correlation coefficient \\
Denoising methods & Correlation coefficient \\
of the first group & & 0.914 \\
\hline Raw data & 0.912 & 0.917 \\
\hline Soft threshold function & 0.915 & 0.922 \\
\hline Hard threshold function & 0.921 & 0.965 \\
\hline Combination of fuzzy control & & \\
\hline filter and theshold function & 0.946 & \\
\hline
\end{tabular}

